\title{
Value Judgments and Value Neutrality in Economics
}

\author{
By PhiLippe Mongin \\ Laboratoire d'économétrie, CNRS and Ecole Polytechnique, Paris
}

Final version received 18 February 2005.

\begin{abstract}
The paper analyses economic evaluations by distinguishing evaluative statements from actual value judgments. From this basis, it compares four solutions to the value neutrality problem in economics. After rebutting the strong theses about neutrality (normative economics is illegitimate) and non-neutrality (the social sciences are value-impregnated), the paper settles the case between the weak neutrality thesis (common in welfare economics) and a novel, weak non-neutrality thesis that extends the realm of normative economics more widely than the other weak thesis does.
\end{abstract}

\section{INTRODUCTION}

Suppose that a sample of economists is asked whether or not the following claims correspond to value judgments:

- The more equal the income distribution, the more just it is.

- In terms of the Gini coefficient, the distribution of income of most countries is less unequal than the distribution of wealth.

- People with less than $\$ 5$ a day are living in a state of poverty.

We may expect a virtually unanimous 'yes' answer in the first case, a widely shared 'no' answer in the second, and divided answers in the third. This pattern is likely to be roughly similar if the poll were carried out with, say, 'There is no goods allocation that is Pareto-dominated'; 'In terms of the Pareto criterion, allocation $\mathrm{X}$ is superior to allocation $\mathrm{Y}$ '; and 'Competitive markets are efficient'. As the imaginary experiment suggests, economists' ideas about what counts as a value judgment and what does not are far from unstructured, but they do leave room for disagreement. One goal of the present paper is to develop a conceptual framework in which those divergent opinions can be restated and assessed.

But why is the question about value judgments interesting? Does it really matter what classifications professional economists make in their reflective moments, as opposed to the work they actually perform? There is a quick answer to this question. It is important to be clear about how judgments of value are to be distinguished from other judgments, because this serves as a logical step towards resolving the so-called value neutrality problem, which any thoughtful economist should arguably be concerned with. This refers to the problem of deciding whether it is possible, and if so whether it is desirable, for economists not to make value judgments in their professional work-as opposed to the value judgments they are welcome to make in their private life and the political arena. (To convey the restriction to professional work, I will use the convenient term 'the economist qua economist'.)

(C) The London School of Economics and Political Science 2006 
The stakes attached to the neutrality problem are so heavy and visible that the profession has long recognized them, even to the point of exaggeration. Many economists take for granted the positivist tenet that only mathematical and factual judgments - and not value judgments - are amenable to rational discussion. Sen (1970, chapter 5) and others have fought against this crude claim, and replaced it with the weaker one that there are marked differences, both logical and rhetorical, between the three classes of judgment. If this is indeed the case, one's vision of economics cannot be the same regardless of whether one construes it as a primarily neutral or primarily non-neutral discipline. No more than Sen's weak claim is needed in order to justify the present investigation into value judgments and value neutrality.

Section I sketches four theses that can conveniently be located along an axis: strong neutrality, weak neutrality, weak non-neutrality and strong nonneutrality. Sections II and III do the necessary groundwork on economic evaluations and prescriptions; these sections are purposefully brief, and some details will have to await another, more technical paper. Building on this basis, Section IV investigates evaluative concepts of economics such as goodness, justice and preference, and Section V swiftly rebuts the strong theses about the neutrality and non-neutrality of economics. The paper draws to a close by settling the case between the non-extreme theses, a sophisticated task that depends crucially on the groundwork. Section VI re-examines the classic distinction, due to Weber and taken up by Robbins, between making a value judgment and taking it as an object of study, and Section VII discusses the related distinction between ends and means that Weber and Robbins also emphasized. These two sections argue that the first distinction is subject to difficulties and the second is essentially irrelevant to economics. In view of the objections, the weak neutrality thesis remains devoid of any supporting argument, and the ground is cleared for the weak non-neutrality thesis. Section VIII concludes that this one does indeed provide the best answer to the value neutrality problem.

\section{Neutrality: A Preview of the Argument}

Historically, theses about the neutrality or otherwise of economics entered the field when Robbins (1932) borrowed his statement of the problem, and the language of value overall, from Weber (1922). ${ }^{1}$ Before this continental shift, the tradition of English-speaking economics had put forward internal divisions based on other philosophical mottos, such as 'science' versus 'morals' or 'ethics', and 'is' versus 'ought'. This earlier tradition culminated with John Neville Keynes's famous trichotomy between the 'positive science', the 'normative science' and the 'art' of economics (the last being roughly what we now call applied economics) (Keynes, 1890). The very first divisions, as in Senior and Mill, had been only twofold, contrasting Keynes's first term with a mix of his last two, so that he deserves credit for introducing the normativepositive cleavage into economics. Remarkably, Keynes's analysis was not displaced by Robbins's imported Weberianism (even his Essay makes some use of it). Subsequent debates have always been couched in both the language of value and the positive-normative distinction - see e.g. Friedman (1953); 
Archibald (1959); Lipsey (1963); Hutchison (1964); Machlup (1978, chapter $9) .^{2}$ The implicit connection is that a statement made by an economist counts as normative if it is paired with a value judgment made by that economist (not somebody else), and as positive otherwise (in particular, it may bear on somebody else's value judgments). This is still today's received view, and it provides an apparently definitive and clear-cut division of economics; thus, I will refer to it as to 'the authoritative criterion'. A more focused paper on value neutrality would have resulted if I could have avoided discussing also the positive versus the normative, but the conceptual embroilment that I just emphasized makes this strategy infeasible. Accordingly, I will approach the value neutrality problem also in terms of the following classic questions: Is normative economics at all legitimate? If it is, should it be demarcated from positive economics? And if it should, how could it be?

The value neutrality problem has received three broad solutions in twentieth-century economics. Thesis 1 bluntly claims that in their professional work economists should always refrain from making value judgments; it expresses the neutrality position in the strongest possible way. Since a prohibition makes sense only if it is possible to violate it, this thesis takes for granted that it is logically possible for the economist qua economist to make value judgments. Using the authoritative criterion as a translation device, one would re-express this by saying that economics either is or ought to be positive (the case of 'is' corresponding to situations in which the question of making a value judgment does not logically arise, that of 'ought' to situations in which the prohibition applies).

Quite remarkably, the strong neutrality position has fostered conflicting assessments of welfare economics. A fierce spokesman of the former, Robbins (1932) wanted to push the latter out of economics into the limbo of 'ethics'; however, his followers at the London School of Economics (LSE) disagreed with him on this score. Archibald (1959) argued that welfare economics was positive in the same sense as, say, unemployment theory, and did not threaten the Robbinsian objective of an entirely neutral economic science; hence there was no point in dismissing it. Today there is a formalistic account of welfare economics, social choice theory and related work such as bargaining theory that leads to a roughly similar conclusion, though by a different route. As the argument goes, welfare economics and similar theories are positive in the sense not of unemployment theory, but of mathematics and logic. It is not the factual or empirical character of these theories, but their complete lack thereof, that supposedly accounts for their neutrality. ${ }^{3}$

Thesis 2 expresses a weaker neutrality position. It starts from the same underlying assumption that the question of making value judgments logically arises for the economist qua economist; but it then claims, contrary to thesis 1, that there are occasions in which he might, and even should, make these judgments. In the other language, one would say that economics might and even ought to be normative sometimes - otherwise it is or ought to be positive, depending on the situation. Beyond these vague generalities, thesis 2 acquires its focus from what I call the containment claim: that those value judgments that economists have a right (and a fortiori an obligation) to make are few in number, easy to discover and logically as well as practically separable from the other judgments that they make. It is not clear how to recast this in 
terms of the positive-normative distinction, but it certainly suggests that the authoritative criterion operates well in concrete situations. Accordingly, I construe the containment claim as implying that, when effectively applied, the authoritative criterion is both exhaustive and exclusive, as any good criterion must be; and, further, that it does not give rise to grossly counterintuitive consequences.

The new welfare economics in its heyday illustrates thesis 2 most vividly. Bergson (1938), Samuelson (1947) and Little (1950) believed that they, and other economists in the field, made - and indeed were justified in making - value judgments. However, the latter were contained, in the sense that they belonged to some kind of standardized list. According to the universally shared value judgment, the Pareto optimum was a particular concept of 'good', and Pareto superiority a particular concept of 'betterness'. Then the new welfare economists would take a stand as to interpersonal comparisons of satisfaction, i.e. whether they should be made and if so, how. (It was another tenet of the time that such comparisons needed value judgments.) Finally, there was a broad commitment towards distributional equality, which the school would qualify in a number of ways.

The new welfare economists' analysis of Paretian concepts needs spelling out, because it has become the established treatment in today's economics. These economists would define Pareto optimality and superiority in terms of either preferences or ordinal utilities, which belong to the individuals' rather than the observer's evaluations, so that by the authoritative criterion these counted as positive concepts. However, the new welfare economists felt that they would not employ the Paretian apparatus, even qua economists, unless they would invest it with 'ethical' interest. Thus, they added to the definition a separable value judgment to connect the Pareto ordering with the 'economic' or 'social' good. While endorsing the new welfare economists' evaluative account of Paretianism, Arrow (1951) argues in effect that their list of value judgments is too thin. ${ }^{4}$ He would like to include value judgments on collective rationality, such as those accompanying the 'independence of irrelevant alternatives' (IIA) condition. There is a substantial disagreement here, but at the formal level at which thesis 2 unfolds nothing distinguishes Arrow from the economists he criticizes. He applies to this novel condition the two-part analysis they apply to the Pareto principle; i.e. he keeps his definition of IIA carefully separate from his value judgment that rational groups should satisfy it. In the hands of many economists, individual decision theory obeys a related pattern. For instance, they would define an individual agent to be someone who maximizes an objective under an availability constraint, and then normally add the value judgment that optimization is an essential part of rationality. ${ }^{5}$

At the other end of the spectrum, thesis 3 denies that economists, whatever their realm of activities, should refrain from making value judgments. In respect of values, what they do qua economists is no different from what they do qua citizens or private persons. The strong non-neutrality thesis often receives a corollary, to the effect that value judgments should be made as openly as possible: what is wrong with them is not that they are made, but that they are usually swept under the carpet. To support these and related claims, the common arguments are that the neutrality recommendation would impoverish the field; that it cannot be feasibly implemented; and even that it 
involves a logical impossibility. In terms of the positive-normative distinction, one would say that economics either is or should be-depending on which argument is selected - normative throughout. Contrary to the other theses, this one was put forward not just for economics, but for the social sciences generally - and, in even more adventurous pronouncements, for knowledge tout court. It reaches a climax with the claim that, when performing logical and mathematical steps, the scientist is still evaluating something.

Thesis 3 has always been more prominent in other social scientists' critiques of economics than within the discipline itself. Those few economists who accept it are a fringe of self-proclaimed heterodoxy, be they neo-Marxist, neoKeynesian or something else. As representative I have selected Myrdal (1958), who belongs to the 'something else' because his claims are not directly political but rather belong to the meta-theoretical level at which I would like to place this paper. Also, as opposed to Mannheim (1936), he does not conflate the problem of value neutrality with that other conundrum, which I do not mean to discuss here - 'science' versus 'ideology'. Even if he does not discriminate well between his various arguments, Myrdal bends towards the only one that, if correct, would be decisive-i.e. that value judgments and judgments of facts cannot be separated logically. This again makes him an appropriate subject for discussion.

The paper propounds a thesis 4, which is not part of the traditional legacy, and may be located, as it were, between the last two; it expresses a weak nonneutrality position. This one starts with the broad claim that the question of making value judgments does arise for the economist qua economist, and that he might, might and should, or might not, make these judgments, depending on the case at hand. This claim clashes with the strong neutrality thesis and fits in with the weak neutrality thesis. The line is drawn with the latter by rejecting its containment claim. I will argue in effect that value judgments in economics are neither easy to spot, nor few in number, nor always separable - practically and even logically - from judgments of fact. In a related move, I will investigate the authoritative criterion and show, on the basis of various problematic examples, that the positive-normative classification it implies for economics is flawed, because it is neither exhaustive nor exclusive, nor free from counterintuitive consequences. However, my critique of neutrality stops a long way from the strong non-neutrality thesis. Myrdal promoted unrestrictedly the view that value and factual judgments cannot be separated logically, whereas I reserve this view for a subclass of economic statements.

Technically, the weak non-neutrality thesis 4 depends on splitting the traditional concept of a value judgment into a statement and a judgment proper. This leads to a two-stage procedure to discriminate between judgments of value and other judgments. The first stage scrutinizes the statement and raises only one question, but a difficult one: what kind of predicates does the statement contain? Some predicates (like just) are clearly evaluative; some others (like more equal in terms of the Gini) clearly are not; and many others are problematic. The second stage, which is of particular interest for statements containing evaluative predicates, involves again only one question, though again a difficult one: is the economist responsible for the judgment associated with the statement? Because this is not always decidable, let alone decidable consistently, the problematic area will increase by a degree of magnitude. The 
two-stage analysis is able to explain why so many economic statements fit in poorly with the positive-normative distinction.

\section{GROUNDWORK ON ECONOMIC EVALUATIONS}

Explaining what separates judgments of fact and judgments of value has proven to be a daunting task for philosophers, and no fully convincing account has yet emerged. Nevertheless, it is only by drawing upon the work done in meta-ethics, deontic logic and analytical philosophy that one could hope to make progress towards the sought-after explication. It is a general suggestion of this paper that economic methodology would benefit from becoming better acquainted with these areas. ${ }^{6}$

I start with a distinction in the style of analytical philosophy. When someone says or writes, for example, ' $\mathrm{X}$ is a good economic policy', one can attend to four different things. There is the sentence itself, which is the linguistic entity; the statement, which is what the sentence means; and the utterance or inscription, which is the material act performed by the speaker or writer. Many analytical philosophers would refine this threefold distinction without worrying about the fourth item, which is the judgment being made. ${ }^{7}$ But my subject matter requires it to be present in the framework. I need it in order to emphasize the speaker or the writer, in a sense not exhausted by the notion of an utterance or an inscription.

Take an actor who says on the stage 'There are more things in heaven and earth, Horatio,...' He makes the same utterance as Hamlet did (supposing for simplicity that Hamlet and Horatio were historical figures, and that Hamlet once uttered the sentence). It seems sensible to conclude that the meaning of the sentence remains unchanged; i.e. the actor is making the same statement as Hamlet did, but he is not making any judgment, whereas Hamlet made one. Sometimes economists are in a position loosely analogous to the actor's: when uttering ' $\mathrm{X}$ is a good economic policy', it is as if they were reciting the sentence. One reason (there are others) for relying on four concepts instead of three is to capture situations of this and related kinds. Without further argument, I will take the view that the statement is not all that matters beyond the sentence; that a judgment goes along with both the sentence and statement; and that the subject of this judgment is not always identical with the source of the utterance or inscription.

The literature of economics and the social sciences, from Weber through Robbins and Myrdal and up to Sen and Arrow, emphasizes value judgments at the expense of value sentences, statements and utterances. In a sense, it presents a defect opposite to that which (for my purposes) analytical philosophy presents. The latter pays too little attention to judgments, be they of fact or value. The historical reason for this state of affairs is that it strongly rejects the older, Aristotelian logic of judgment in order to embrace the modern logic of quantifiers, predicates and operators. Conversely, the neglect of linguistic features in the literature on economics and social sciences can only be explained by its indirect reliance on the older logic - a surprising anachronism in the late twentieth century. Things being as they are, one challenge of this paper was to bring these two streams of thought together. 
When I say 'evaluation', I mean any of the four items discussed above when a judgment of value is made. (It would help to have a common word also when a judgment of fact is made, but there appears to be none.) I wrote 'statement' where some would recommend 'proposition', and there is a substantial reason for this terminology. Philosophers take it to be a defining feature of propositions that they have truth values, and it is contentious whether evaluations are either true or false. In meta-ethics, the positivist and emotivist schools on the one hand, and the intuitionist and cognitivist schools on the other, clash over this major issue; other schools have their own complicated answers. Because positivism was so influential on the way Friedman and Samuelson described normative work, and emotivism inspired Little's (1950) reconstruction of welfare economics, ${ }^{8}$ I might be expected to take a position. But that would require another paper, and fortunately it is possible to make progress on the value neutrality problem without first solving the truth value problem.

Now comes the main technical proposal, which was foreshadowed in last section. At stage 1 of the analysis, I say of a non-analytical ${ }^{9}$ statement that it is logically evaluative if it makes use of at least one evaluative predicate, at least one of them being factually logically factual if it makes use of predicates that are all factual or logical, and logically neutral in remaining cases. By this definition, to diagnose the statement expressed by the sentence 'Economic policy $\mathrm{X}$ is a good one' reduces to diagnosing the predicate good. Stage 2 narrows the analysis down to those statements that are declared to be either logically evaluative or logically factual. Only then is it relevant for the present purposes to raise the question, does the economist make a judgment? Let us say that the economist makes a judgment of value if the statement is logically evaluative and the economist sincerely asserts it; that he makes a judgment of fact if the statement is logically factual and he sincerely asserts it; and that he makes no judgment at all if he does not make a sincere assertion. Thus, granted that by a stage 1 decision 'good' means an evaluative predicate in ' $\mathrm{X}$ is a good economic policy', one will at stage 2 ask whether or not the economist judges that $\mathrm{X}$ is a good economic policy, and this will be answered by deciding whether or not he is sincerely asserting the corresponding statement. The assertion condition would be sufficient to solve the Hamlet problem in its pure form, since the actor does not assert anything on the stage, but I added a sincerity requirement in order to handle analogical forms of this problem in economics (I discuss below the case of a central banker). Some philosophers will no doubt question my criterion of judgment, but its intent should strike them as plain and acceptable: roughly speaking, I want to dispose of those statements that economists make without really meaning them. As it stands, stage 2 is defined only for elementary statements like the present example. Something will be said later regarding two prominent classes of complex statements, i.e. conditionals and belief statements.

I now need to make some clarifications about stage 1 . The difference between statements and sentences comes in handy here, because a given statement can be associated with different sentences that express it more or less appropriately. To continue the example, 'Economic policy $\mathrm{X}$ is good' does not convey the economists' evaluative meaning of 'good' so well as ' $\mathrm{X}$ is a good economic policy', since the good they have in mind is not absolute, as in 'Love 
is good', but relative to what economic policies have in common. One may assume that for each statement there is a canonical sentence to express it. The analysis must be carried out in terms of this sentence alone, and if the ordinary language seems too ambiguous to formulate it, there will some point in resorting to one of the artificial languages of contemporary logic.

The proposed taxonomy of statements at stage 1 excludes analytical statements, by which I mean, following the usual philosophical definition, those statements that can be declared true or false by virtue of the meaning of their constituent terms. ${ }^{10}$ Logical truths are a particular case, since they are true in virtue of the meaning of their logical constituent terms. The definition also covers those statements that depend for their truth or falsity on the meaning of their non-logical terms, such as that equilibrium is a state of rest; or that to be equitable is to treat equals equally. For one reason or another, mathematical theorems are usually counted among analytical statements. There seems to be little point in asking either stage 2 or even stage 1 questions $v i s-a ̀-v i s$ analytical statements; hence I excluded them at the outset. Simplifying the terminology, I will lump them with those non-analytical statements that stage 1 classifies as being logically neutral. I now move on to this class.

Crucially, the evaluative or factual predicate has to be genuinely used if the statement is to count as being logically evaluative or factual. In terms of another classic distinction, the canonical sentence must use, and not merely mention, the relevant predicate symbols. However, as Hare (1952, pp. 124-5) has argued, the distinction must be handled with care when it comes to evaluative predicates.

Two examples support his point. Unambiguously, the sentence " "Just" is a four-letter word' expresses a logically factual statement. Contrast it with " "Just" means "distributionally equal".' In many contexts this sentence will express a logically evaluative statement, even though the predicate word is again mentioned, not used. The discrepancy comes from the fact that 'Justice is distributional equality' would be the canonical rendering for these contexts. Inverted commas in a sentence are not sufficient evidence of mention. Conversely, and more subtly, the absence of inverted commas is not sufficient evidence of use. An example of this can be adapted to economics. Although doubting that Paretianism captures the social good adequately, I might still say ' $\mathrm{X}$ is better than $\mathrm{Y}$ ' instead of ' $\mathrm{X}$ is Pareto-superior to $\mathrm{Y}$ ', meaning something like ' $\mathrm{X}$ is Pareto-superior to $\mathrm{Y}$, and welfare economists would add that $\mathrm{X}$ is better than Y.' My statement alludes to a logically evaluative statement made by other people that I happen to have in mind. This elliptical way of conveying my meaning is acceptably unambiguous in some relevant contexts: suppose that I am giving a welfare economics paper to a welfare economics group, and that I want to make a purely technical point, without questioning the philosophical commitments of my listeners. This and similar examples support Hare's point that one should be prepared to take a generous view of mention, and a restrictive one of use, when analysing the evaluative language. I conclude that logically neutral statements will constitute a wide-ranging category.

Although they are related to disguised quotations, belief sentences call for a separate analysis. 'Mrs Thatcher believes that active trade unions are bad for the economy' has a very different meaning from 'Mrs Thatcher says: "active trade unions are bad for the economy".' The predicate bad, which is mentioned 
in the second case, is used in the first. Accordingly, I will treat belief sentences containing evaluative words as expressing logically evaluative statements. The commonsense intuition that they do not correspond to value judgments made by the speaker will be captured by suitable stage 2 decisions. Concerning the statement expressed by the first sentence, the conclusion will be, as it should, that only Mrs Thatcher, and not the economist, is making a sincere assertion that matches a value judgment. Having sketched a distinctive treatment for disguised quotations and belief sentences, I should none the less emphasize that there are many borderline cases. ${ }^{11}$

I now discuss stage 2 in terms of a few representative examples. Suppose the following sentences were borrowed from economic texts, in which they were not in inverted commas:

(a) 'Some economists believe that to increase the interest rate is a good economic policy.'

(b) 'Some economists believe that to increase the interest rate is a good economic policy. But they do not realize that it would slow down the present recovery, which would be a bad consequence.'

(c) 'Erik believes that I, the author, am mistaken in believing that to increase the interest rate is a good economic policy.'

I assume again that in these sentences 'good' means an evaluative predicate. Now, if the information concerning (a) were limited to that very sentence, the prima facie view would be that the author does not make any value judgment at all. However, the surrounding linguistic context may provide a different clue, as the next example illustrates. The addition in (b) strongly suggests that the economist is taking a stand on the proposed policy, since he himself attributes a bad consequence to that policy. However, further contextual information, either linguistic or external, might upset the commonsense conclusion. Suppose that the author of (b) were Alan Greenspan. Clearly, it would not be the same if the sentences had been inscribed by the young academic Greenspan in the American Economic Review or by Chairman Greenspan in a press release of the Federal Reserve Bank. Greenspan would presumably mean to convey something to the markets. For instance, he might be willing to forestall a rise in the exchange rate of the dollar because of the prevailing expectation that the Fed is going to raise the interest rate. It may even be that Greenspan believes it would be a good thing after all if the recovery were slowed down, and is suggesting the contrary only because that will help him make it clearer that he does not intend to raise the interest rate! If this were the case, Greenspan would make a logically evaluative statement insincerely. This roundabout, but roughly plausible, example extends the Hamlet problem one step further: neither the actor nor the central banker makes the value judgment corresponding to the statement they make, but Greenspan asserts something whereas the actor only recites a text. This is why I introduced the sincerity requirement in the analysis of stage 2 attributions.

Examples (a), (b) and even more clearly (c) bring out the difficult problem of extending this analysis to belief statements. I conceive of stage 2 decisions as being concerned not with all and every statement that can be retrieved from (a), (b) and (c), but only with this one: increasing the interest rate is a good 
economic policy. More generally, I suggest dealing with belief statements in terms of the following algorithm. Decompose them until you reach all their elementary sub-statements, i.e. those sub-statements that do not contain any belief operator, and to those alone apply the two-stage analysis. While this method makes good sense, I cannot ascertain that it will always deliver all the judgment values that can be made in relation to a belief statement, especially if the latter is nested as in (c). It may be that Erik's higher-order belief involves evaluating the first-order belief (and me who holds it) as irrelevant or stupid. If this is the case, value judgments will be associated with the full statement itself, and not just with its elementary sub-statements.

The analysis should also be extended to conditional statements. Consider for instance

(d) 'If markets are competitive, they are efficient.'

In economics, the predicate efficient ranges on a wide array of meanings, some of them clearly factual, others frankly evaluative, still others ambiguous. On some well known interpretations of efficient, market and competitive, the sentence expresses an analytical statement, i.e. the first fundamental theorem of welfare economics, and the investigation does not even reach stage 1 . On other construals, depending mostly on what is being decided for efficient, (d) will express either a logically evaluative or a logically factual statement; and, supposing that the economist sincerely asserts it, this will give rise to opposite conclusions at stage 2 .

This example suggests a few generalities. First, non-nested conditionals must be taken as a whole, since there is no sense in applying the two-stage procedure to their antecedents and consequents separately. Second, nested conditionals raise the same problem as nested belief statements: i.e. there may or may not be value judgments specifically connected with the whole as opposed to those accompanying its component parts. (Consider the following: 'If it is the case that if markets are competitive they are efficient, then it is good to abolish tariffs.') Third, many conditional sentences call for an analytical interpretation, which luckily cuts short the more advanced discussion. Among the analytical conditionals are not only the theorems of mathematical economics, but also the statements that economists obtain by establishing meaning connections; think of the biconditional that to be equitable is to treat equals equally.

\section{A WORD ON ECONOMIC PRESCRIPTIONS}

Evaluations, it seems, trigger prescriptions. If I claim that $\mathrm{X}$ is a good economic policy and $\mathrm{Y}$ is bad one, and if there is an action to be taken that might favour one against the other, my claim suggests that it is $\mathrm{X}$, not $\mathrm{Y}$, that should be promoted. Meta-ethical systems have elaborated on this linkage a great deal. This makes an extension of the groundwork to cover economic prescriptions unavoidable. $^{12}$

Compare the statements expressed by (a) ' $\mathrm{X}$ is the best economic policy' with (c) 'Society should implement economic policy'. Or compare (b) ' $\mathrm{X}$ is a better economic policy than Y' with (d) 'Society should implement economic policy X rather than Y'. Both (a) and (b) express evaluations, whereas (c) and 
(d) express prescriptions. Deontic logicians (e.g. Kalinowski, 1972; von Wright, 1983) have established a demarcation line: the statements expressed by (c) and (d) do not have the same logical form as those expressed by (a) and (b). Evaluations have a predicative form-i.e. they are logically formalized in terms of $n$-place predicates - but prescriptions have a modal form-i.e. they are logically formalized in terms of a modal operator ('it is obligatory that') acting on sentences.

However they may differ in syntactical form, evaluations and prescriptions may well be close to each other in semantic and pragmatic respects. There is indeed a classic meta-ethical view, shared by Husserl, Hare and many others, that at least moral evaluations cannot be separated from corresponding prescriptions. The underlying argument is that I cannot declare an action $\mathrm{X}$ to be morally best without implying that one should do $\mathrm{X}$ under the proviso that $\mathrm{X}$ is feasible. (A variant can be devised for 'morally better', but I will concentrate on the simple case.) Allegedly, the implication is semantic; i.e. the meaning of 'morally best' and 'should' is what permits the derivation of one claim from the other.

This argument seems hardly applicable to economics, which is not concerned with the morally best or better. However, the notion that evaluations semantically entail prescriptions is also endorsed by utilitarianism, which is not so fussy about what counts as a moral claim and what does not, and utilitarianism is a doctrine of perennial influence among economists. Sen (1979) conveniently factors it out into three components: (i) the making of interpersonal comparisons of a certain kind, (ii) welfarism and, (iii) what is relevant here, consequentialism. By definition, consequentialist theories derive their notion of a right action from the more basic notion of a best state of affairs. The notion of a right action is only one step away from that of a prescription. For a consequentialist, who has already made the step from ' $\mathrm{X}$ is the best economic policy' to ' $\mathrm{X}$ is the right economic policy to take', the final step to 'Society should implement economic policy $\mathrm{X}$ ' seems quite unproblematic. Hence utilitarianism, or rather consequentialism, provides another link connecting economic evaluations with prescriptions. However, the consequentialist argument raises many philosophical problems of its own, which means that it may not yet be the argument that economics needs. There are other views available, but they would deliver the sought-after connection no more convincingly than consequentialism does.

In view of this inconclusive attempt at tying up prescriptions with evaluations, one had better not play down their prima facie differences. If common sense suggests a linkage of the two, it also accepts that they are not the same ideas. The warning needs emphasizing because economists often overlook it. Witness Archibald:

We have a single dichotomy in economics, between positive enquiries into how something may be done, and normative recommendations that it should be done.... Positive and normative are separated in employment theory by a value judgment such as that 'we should try to maintain full employment' (rather than, e.g., stable prices). (Archibald, 1959, p. 321; my emphasis)

It may be that genuine prescriptions sometimes emerge from normative economics, but Archibald's full employment example is clearly no such a case. 
He should say that 'a state of full employment with some inflation of the economy is better than a state of underemployment with no inflation', or that 'it would be a good thing if one could maintain full employment, even if this involved paying an inflationary price'. I suspect that Archibald would grant the point, but dismiss it as being unimportant. On the contrary, it can be shown that this clarification matters both to the philosophy of economics and to economics itself.

When value judgments are redefined so as to include prescriptions, it becomes tempting to overplay the role of the latter within the enlarged category. Archibald's first sentence, which contrasts 'positive enquiries' with 'normative recommendations that (something) should be done', exemplifies this trend: evaluations properly defined vanish from his suggested division of economics. ${ }^{13}$ The next step, which many economists take, consists in invoking Hume's (1739) thesis: from an 'is', no 'ought' correctly follows (see Treatise on Human Nature, III, I). Since Hume's divide seems to be sharp and definitive, economists often end up founding the positive-normative distinction on it, rather than on the required analysis of value judgments. They leave the authoritative criterion unexamined, while the neater logical argument monopolizes their attention. The problem of value neutrality retains its Weberian formulation, but its solution is allegedly forthcoming in Humean terms! I have found evidence for this replacement strategy among virtually all defenders of the extreme neutrality thesis, plus a few others. It cannot be decisive, because the best that Hume's thesis could achieve would be to set aside from positive economics only the prescriptive part of normative economics. It may or may not be the case that variants of Hume's thesis adapted to evaluations illuminate the value neutrality problem; this question is explored in another paper, where it receives a negative answer. What the present paper denies is that the strategy in its initial, crude form works. Section $\mathrm{V}$ shows that this denial is sufficient to block Robbins's plea for strong neutrality.

Taking one further step, I will argue by means of an example that to conflate prescriptions with evaluations fosters not only philosophical confusion about economics, but also theoretical confusion within economics. Consider the famous $k \%$ rule of monetary growth that was 'recommended' by Friedman (1968). What exactly was its status? It seems fair to say that there was no genuine agreement among those monetarist economists who, for at least some years, followed Friedman in 'recommending' it. Some apparently believed that the money supply was an instrument variable, and then took the rule to be bluntly prescriptive. Others knew that the money stock was more of the nature of an objective than of an instrument, and for them the rule enjoined the central bank to take whatever steps were appropriate in order to achieve a $k \%$ annual increase in the money stock. With this interpretation, the $k \%$ rule remained prescriptive, but in a different way: suppose the central bank had taken appropriate steps and none the less had failed to achieve a $k \%$ increase; then it would not have failed its obligation. Other monetarists believed the rule to be simply a means to achieve the only truly significant prescription, which was 'Avoid unnecessary inflation'; and still others might have understood it more like an evaluation - it is a good thing if the central bank achieves a $k \%$ annual increase. The problem with this famous rule was not so much that those 
who 'recommended' it disagreed among themselves as that they did not have the concepts to describe their lack of agreement.

\section{Good And the Evaluative PredicAtes of ECONOMICS}

This section is concerned with stage 1 decisions, i.e. with the predicates of economics. I tackle the problem they raise - are they evaluative or not? - by discussing a few major examples in turn, starting with good and its relational forms.

Earlier, I suggested that those economists who uttered 'Economic policy $\mathrm{X}$ is good' really meant ' $\mathrm{X}$ is a good economic policy', which is to say more explicitly, 'Economic policy $\mathrm{X}$ is good qua economic policy.' This can be formalized in terms of a classic distinction of meta-ethics. Economics makes attributive use of the predicate good, to be contrasted with its predicative use, as in 'Love is good', which, if at all significant, must be reserved for ethics. Those philosophers like Geach (1956), who claim that the attributive use is automatically descriptive, would conclude that there is no evaluative good in economics. However, their claim is prima facie implausible. The descriptive interpretation works for sentences like ' $\mathrm{X}$ is a good hygrometer', but not for, say, ' $\mathrm{X}$ is a good sunset'. Hare (1957) argues from this contrast that a necessary condition for 'good' to be descriptive is that ' $\mathrm{X}$ ' in the sentence must be a functional word, i.e. a word the definition of which explains what $\mathrm{X}$ is for. To say what an economic policy is for, one has to have a theoretical outlook as well as moral and political commitments; it is clearly not enough to know the meaning of 'economic policy'. The expression is not functional, and in the end comes closer to 'sunset' than 'hygrometer'. I may conclude that there are clear and important occurrences of the evaluative good in economics. (Of course, this does not preclude cases of descriptive good.)

It would be a mistake to believe that, with the last claim, the ethical good re-enters economics by the back door. To attribute that kind of good to a thing or state of affairs requires one to take into account and weigh against one another the various goodness considerations of the case. By contrast with this 'all-things-considered' notion, economists concentrate on just a few aspects of what is good or bad in a thing or a state of affairs. They typically indicate the restriction by saying 'economic such-and-such' (in early welfare economics) or 'social such-and-such' (in social choice theory and later welfare economics). Economists employ these two adjectives as modifiers of 'welfare', which they often take to be another expression for 'the good', as Sen (1991, p. 15) aptly points out; so it is worth briefly discussing how they define 'economic welfare' and 'social welfare'.

According to Pigou (1920), the former was 'that part of welfare that can be brought into relation with the measuring rod of money'. This famous definition turned out to be too narrow, but is useful in revealing the economists' policy of selecting just a few aspects of the good for consideration. Graaff (1957) went beyond Pigou by saying that 'economic welfare' was a subspecies of 'general welfare', and further tried to explicate the difference between the two in terms of various causes acting on welfare, some of them economic and others not. Again, this was too specific a construction, but it testifies to the profession's 
intellectual strategy. Under Arrovian influences, the expression 'social welfare' has come to displace 'economic welfare' even in welfare economics. It still carries definite restrictions with it. Economists have enlarged the meaning of the good they considered earlier by including collective rationality considerations into it, but even so they stop a long way from an 'all-things-considered' conception. To illustrate, think of the educational view of the state as teaching the citizen to be more virtuous and knowledgeable. It seems as if even the most resolutely liberal theories of the state will include a modicum of this view, so one feels authorized to make it part of the conception of the collective good. However, standard social welfare functions cannot possibly take it into account, since they depend on fixed individual preference data, whereas the educational view would require these data to evolve.

In sum, the location of the economic good on the philosophers' map appears to be this. It is always attributive, often non-functional, and in this non-functional quality it is evaluative, implicitly restricted and different from the ethical good. For the position I am trying to articulate, it is important to stress the last feature. To de-emphasize economic prescriptions, as I did in last section, would be problematic if it were the case that economics did after all use the ethical good. This does not imply, of course, that the economic good might be ethically irrelevant: on the contrary, to the extent that it summarizes partial goodness considerations, it does matter to the ethical good.

There are many evaluative predicates beside good, and I move on to those that may be called thick, after Williams (1985, p. 140). Their defining feature is that they have an evaluative and a descriptive side at the same time. As Williams and others have argued, these two sides are as inseparable as those of a coin; any attempt to extract the descriptive from the evaluative is bound to distort meanings unacceptably. Ethical examples include courageous, honest, liar, grateful. It is a minor innovation of this paper to extend the thickness concept to evaluations made in economics and the social sciences. The ethical good is the usual candidate for thinness, i.e. the opposite property of being exclusively evaluative. Some have argued that it is thick after all, though not as thick as, say, courageous, and that it would be easy to devise a similar argument for the economic good. However, there are more obvious examples of thick economic predicates, and I briefly discuss them now.

Just calls for a preliminary analysis that is very roughly analogous to that carried for good. This predicate functions in economics differently from the corresponding ethical concept-moral justice - though it is relevant for this concept since economic justice contributes towards moral justice. This again reflects the policy of economists to impose semantic restrictions. They relate justice to distributive issues almost exclusively, neglecting corrective and commutative justice, which, by contrast, are central to legal theory. Further, although today's economists do not limit attention to money income and commodity bundles, the range of items they consider for a just distribution remains limited. The two restrictions, along with the historical fact that economists tend to connect distributive justice with equality, shape a specialized meaning for just and its variants, equitable, fair, etc. By the same token, these predicates are thick. In a number of contexts of economics, the statement that $\mathrm{X}$ is a more just state of affairs than $\mathrm{Y}$ must be understood as implying the descriptive statement that the distribution of goods or money is closer to equality in $\mathrm{X}$ than in $\mathrm{Y}$.

(C) The London School of Economics and Political Science 2006 
Rational is clearly evaluative in economics, but does not belong to the same group as just because it does not have any direct ethical counterpart. Accordingly, it can at most be invested with indirect ethical relevance. In other respects, rational is not unlike just. The meaning of this predicate depends on restrictions, some of them stipulated, others implicit, which load it with a descriptive content. It is thick to the point of allowing predictive use in relevant circumstances.

I single out a less noticeable class of thick predicates of economics, which have the peculiarity of applying both to states of affairs or actions and to statements made about these items. Common examples involve relevant, acceptable, satisfactory, defensible, reasonable, compelling. Ordinary conversation allows for 'this is a relevant action to take' as well as 'your comment is relevant'. In contrast, economics tends to employ a more specialized evaluative vocabulary at the first-order level, reserving 'relevant' and related expressions for second-order evaluative use. How this works is nicely illustrated by Arrow's (1951) handling of the assumptions for his Impossibility Theorem. He is careful to phrase the assumptions technically, but then comments on them using the previous predicates; his assessment actually goes across the whole spectrum of approbation, from 'relevant' to 'compelling'. What descriptive content such predicates have depends in part on what they imply about first-order items, in part on acquired meanings. For instance, Arrow would argue that nonimposition is compelling, given the free-market democratic societies to which he is restricting his attention.

Readers might expect me go beyond the stage of giving examples and making internal classifications: surely, the basic objective is to become able to recognize whether or not a predicate of economics has an evaluative side. While admitting that I do not provide a criterion, I stress that philosophers have done no better. What their work offers is a list of necessary conditions for a statement to count as an evaluation that have the extra property of not being also necessary for the statement to count as a statement of fact. I now give a quick summary of the proposed items. (Some are more questionable than others.)

Evaluative predicates, and then evaluations, are comparative. They come in a gradation. They make implicit reference to a reference point, and comparisons between objects are secondary to comparisons between the objects and this yardstick. The latter is often located at the positive extreme of the gradation, like an ideal; however, it may sit towards the middle, like a standard of normality, or even at the negative extreme, like an absolute foil. Evaluations are subjective in the sense that they presuppose a subject to make them, and perhaps even in the stronger sense of being completely specified only if the subject who makes them is indicated. An evaluative predicate is never equivalent to any list of descriptive predicates, but depends - in the sense of a mathematical function - on one such list. ${ }^{14}$

Consider elementary statements such as are expressed canonically by ' $\mathrm{X}$ is P': empirical evidence is not relevant to them in the same way, whether ' $\mathrm{P}$ ' means an evaluative or a descriptive predicate. Specifically (this condition is central to Friedman's and Lipsey's drawing of the positive-normative distinction), elementary evaluative statements are empirically irrefutable in some circumstances in which elementary descriptive statements would be 
empirically refutable, and disagreements about primitive evaluative statements are left unresolved in some circumstances in which disagreements about elementary descriptive statements would be resolved. Finally, I have mentioned the claim made by some philosophers that there are entailment relations between evaluations and prescriptions. Here I retain the much weaker point that evaluative predicates are somehow connected in terms of meaning with action-predicates.

All these candidates are important prima facie. I will make the logical and argumentative jump from those unanalysed suggestions to the following conclusion. Evaluative predicates share some universal properties that descriptive predicates do not share to the same extent, and the previous list provides a rough indication of these properties. No set of necessary and sufficient conditions for an evaluation is known, none of the necessary conditions is very informative when taken in isolation, and any set of them remains open to doubts; but the present list tells us something suggestive in the end. (A related and slightly weaker claim is that the presence of the logically evaluative can often be recognized in actual practice. Although there are many borderline cases, most of us are perhaps not too bad at deciding where a given predicate belongs).

It is a further jump, though perhaps not a major one, to the conclusion that the economic concept of preference is evaluative. The predicate that economists mean by 'is preferred to' passes the rough-and-ready test of the necessary conditions above. Like the ordinary language predicate, that of the economists is comparative and admits of gradations. It does not involve a yardstick in every circumstance, but it sometimes does (e.g. when the consumer has a satiation point, or there is some 'golden rule' of action). It has become a tenet of economics since Pareto and Hicks that preferences are subjective, and they are usually indexed by individual bearers. As is the case with ordinary preference, the economists' predicate depends, in the mathematical sense, on descriptive properties of the things it compares, but it does not mean these descriptive properties. Last but not least, the economists' preference is actionrelated to the extent that it connects with choice. The exact connection is a matter of dispute, but the main competing construals appear to share the view that preference and choice are linked to each other in terms of their meaning and not accidentally, which is all I need as far as this condition goes. It entails that empirical observations about choices are relevant; how strongly this evidence counts depends on the particular construal.

The claim that preference counts among the evaluative predicates of economics is likely to cause misunderstandings that I had better clear up now. Suppose that I utter the sentences (S) 'I prefer Burgundy to Bordeaux wine' and $\left(S^{\prime}\right)$ 'Dan prefers Bordeaux to Burgundy wine'. According to the commonsense view of this example, I make a value judgment in the former case, and not in the latter. How can one recover common sense in the present framework? A conceivable answer is that the preference predicate, being ambiguous in general, conveniently turns out to be evaluative in (S) and nonevaluative in $\left(\mathbf{S}^{\prime}\right)$. However, this answer is easy to reject. The standard way to make the preference predicate non-evaluative amounts to interpreting ' $i$ prefers A to B' as meaning ' $i$ chooses A rather than $\mathrm{B}$ whenever $i$ is given the choice between $\mathrm{A}$ and $\mathrm{B}$ '- this is the revealed preference semantics of preference. 
Most philosophers of economics and not a few economists reject this semantics as inadequate. ${ }^{15}$ And even if the revealed preference semantics were not flawed, a formal point would still apply: the same semantics cannot be adopted for $\left(S^{\prime}\right)$ and dismissed for (S). It cannot be the case that the meaning connection of preference with choice is tight when I quote or report on Dan, and suddenly loosens when I speak for myself.

A more promising line about $(S)$ and $\left(S^{\prime}\right)$ emphasizes the intuitive difference between expressing and reporting on a preference judgment. In marked contrast with the earlier one, this argument presupposes that the preference predicate is always evaluative. Given that the predicate is used, and not just mentioned, in both (S) and $\left(\mathrm{S}^{\prime}\right)$, the decision is pushed from stage 1 to stage 2 for either sentence. In order to achieve the final separation, I propose to understand preference in the following way: to prefer $X$ to $Y$ is to believe that $X$ is preferable to $Y$. This is an unconventional but relatively noncommittal semantics; in particular, it need not sever the links between preference and choice. The point is to turn preference statements into particular cases of belief statements. Then the decision procedure sketched for the latter becomes available, with the opposite results one would hope for. In the case of (S), I sincerely assert a logically evaluative elementary sub-statement (Burgundy is preferable to Bordeaux) but nothing of the kind occurs with $\left(\mathrm{S}^{\prime}\right)$.

\section{The Strong Neutrality and Non-Neutrality Theses}

The analysis of stage 1 is virtually all that is needed in order to dismiss the two extreme neutrality and non-neutrality theses. Admittedly, they appeared to be implausible at the outset. But it is important to fill out the argument against them in a way that agrees with the groundwork and prepares for the more advanced conclusions to come relative to the non-extreme theses.

The following passage by Myrdal summarizes the case for the strong nonneutrality thesis 3:

A disinterested social science has never existed and, for logical reasons, cannot exist. The value connotations of our main concepts represent our interest in a matter, give direction to our thoughts and significance to our inferences. It poses the questions without which there are no answers ...

The recognition that our very concepts are value-loaded implies that they cannot be defined except in terms of political valuations. It is indeed on account of scientific stringency that these valuations should be made explicit. They represent value premises for scientific analysis; contrary to widely held opinions, not only the practical conclusions from a scientific analysis, but this analysis itself depends necessarily on value premises. (Myrdal, 1958, pp. 1-2) ${ }^{16}$

Not everywhere does Myrdal equate evaluations with political evaluations (cf. 1958, p. 54), so I ignore an addition that could only weaken his case. Essentially, he makes two points. First, evaluations are pervasive because they are connected with the social scientist's selective interest in the scientific material and his way of making sense of it. Second, evaluations play a semantic role (concepts are defined in terms of evaluations) as well as an inferential role (unstated evaluations are like missing premises). A third claim in the form of a 
recommendation, which is typical of Myrdal, does not surface explicitly in the quote: social scientists should state their evaluations as clearly and completely as they can.

The first claim is crucial to the other two, and even the most generous reading cannot make much of it. If it means that one cannot be seriously interested in an object, or make a selection relative to that object, without evaluating some or all of its features, the claim is simply false. It is possible - in the sense of both 'logically compatible' and 'actually feasible' - for an economist to investigate income inequality in France without feeling that there is anything good, or anything bad, with the French income distribution. The fact that inequality theorists usually feel strongly about inequality belongs to sociological observation, and is irrelevant to the point. Now, if the claim means that to express an interest in inequality theory involves evaluating its relevance favourably, the claim becomes unobjectionable; but it then asserts very little. It does not separate the social from the natural sciences, contrary to the suggestion; and worse, it provides no basis for making the second and third claims. It is implausible that evaluations of the I-find-my-field-interesting style seriously interfere with meanings and inferences, and nothing would be gained from publicizing them.

One way or another, the criticisms of the last paragraph have been made several times. ${ }^{17}$ I had to echo them, but, in the framework of this paper there is a neater point to stress. Not everything in economics can be evaluative, simply because not every predicate of economics is evaluative. Some (though not all) economic measures are descriptive, and accordingly enter logically factual statements. Phillips's (1958) measures of unemployment and inflation in the historic paper strike today's econometricians as being poor and even biased, but I have never seen them being criticized on the ground that they were directed by evaluations. That Phillips selected the time lags that would deliver a nicely downward-sloping curve is an objection very different from the Myrdalian one that his selection was guided by a value judgment. Readers who remain suspicious of complex measures like these are welcome to think of tons of cement, numbers of supermarkets or income tax rates.

The strong neutrality thesis 1 is epitomized in a well known passage by Robbins:

'Economics', says Mr. Hawtrey, 'cannot be dissociated from Ethics.' Unfortunately, it does not seem logically possible to associate the two studies in any form but mere juxtaposition. Economics deals with ascertainable facts; ethics with valuations and obligations. The two fields of inquiry are not on the same plane of discourse. Between the generalizations of positive and normative studies there is a logical gulf. ... Propositions involving the verb 'OUGHT' are different in kind from propositions involving the verb 'IS'. (Robbins, 1932, in 1935, pp. 148-9)

As with Myrdal, it needs some generosity to go beyond the bullish style and isolate analysable claims. The more visible of these is that the value neutrality problem is solved by Hume's thesis about 'is' and 'ought'. If my argument against the replacement strategy is correct, Robbins and his followers lose a crucial weapon in their armoury. By a symmetric mistake, the non-neutrality theorists often directed their fire at Hume's thesis, as if this would be sufficient 
to debunk the enemy (see Myrdal, 1958, pp. 9 and 48, and the comments by Streeten).

A secondary claim in Robbins is that economics should be separate from ethics. To the extent that there is more than Hume's thesis underlying this claim, it becomes another defence of his position. Instead of rebuking it directly, I will argue that, even if it were granted, the consequence that normative economics is illegitimate would not follow. The jump comes from the thought that ethical evaluations are the only ones to be considered. But some evaluative predicates of economics are not ethical - one example being rational-and create room for a kind of normative economics that eludes Robbins's dichotomy between economics and ethics. To avoid this non sequitur objection, he would have to make absurd claims, e.g. that economists do not genuinely use the predicate rational, or that it enters statements they do not sincerely assert. Bizarrely, Robbins recognized that an agent's ordinary preferences were evaluations of a non-ethical sort, but when it came to economists, as opposed to agents, he forgot about this logical possibility. His 'ethical' opponents based their view on the same omission, and, regrettably, it also infects the work of weak neutrality theorists such as Bergson and Samuelson. ${ }^{18}$

For the LSE economists who followed Robbins, his strong neutrality thesis was compatible, despite appearances, with the programme of the New Welfare Economics; allegedly, it was sufficient to reinterpret the latter appropriately (see Lancaster, 1958, and Archibald, 1959). ${ }^{19}$ I turn to this argument, which still enjoys some popularity today. The reinterpretation is to be furnished by the revealed preference semantics. Applying it to 'State X Pareto-dominates state $\mathrm{Y}$ ', one gets a new sentence that makes a logically descriptive statement:

States $\mathrm{X}$ and $\mathrm{Y}$ are such that, whenever the individuals are given the choice between the two, all choose $\mathrm{X}$ rather than $\mathrm{Y}$.

In order to recast the notion of a general optimum, one first takes it to mean a Pareto optimum, and then applies the previous translation. The resulting notion is, roughly, a state that would be among the unanimously chosen ones if it were feasible. Since the New Welfare Economics centres on the marginal conditions for a general optimum, the bulk of its work can now be claimed by positive economics. Archibald goes so far as to say that the reinterpretation transforms the first fundamental welfare theorem into an empirically refutable statement.

A point to be clarified is what the choice-based factual construals are intended for. On one reading they are meant to replace the initial formulations; on another they are meant to coexist with them. If the weak reading is adopted, the New Welfare Economics will live in two locations separated by a Robbinsian line: economics when the revealed preference semantics prevails, and something else than economics otherwise. If anything, this ubiquity speaks against the way of drawing the line. Only the strong reading is consistent, but it raises the objection that the choice-based semantics deprives welfare economics of its theoretical significance. Take the first welfare theorem. Archibald's refutable version holds little interest; the best it can offer is a roundabout way of testing whether some economic state is a competitive equilibrium, while direct methods are more to the point. By contrast, the statement of the theorem 
using Paretian concepts matters a great deal, and what is important about it can be explained only in a logically evaluative way. It may be that welfare is not what matters about a Pareto optimum, but whatever else there is-say, efficiency or freedom - must again be stated evaluatively. Granted this easy point, the dismissal of the LSE doctrine is completed by arguing that the discussion about what matters should take place within welfare economics, not elsewhere; this seems to be another easy step to make.

Importantly, the dismissal here does not depend on the philosophical claim that the revealed preference semantics is inadequate. It also works against the formalistic argument for strong neutrality that has become widespread today, i.e. that the statements of welfare economics are just mathematical ones, and for that reason the field does not belong to normative economics. I can now move on to the next item on the agenda, i.e. the weak neutrality thesis 2 .

\section{Studying a Value Judgment and Making One}

As is well known, Weber (1922) promoted the basic distinction between making a value judgment, as when someone says ' $\mathrm{X}$ is good', and taking it as an object of study, as the same person would do when investigating, reconstructing or trying to explain this judgment. By promoting the distinction among economists, Robbins renewed their understanding of Keynes's earlier demarcation. They implicitly adopted what I called the authoritative criterion, which says that a statement made by an economist counts as normative if the accompanying judgment is a value judgment made by that very same economist, and as positive otherwise. My strategy will be to show that Weber's distinction does not ground a satisfactory division of economics; this amounts to rebutting the authoritative criterion. I will point out cases of economic statements which, if the criterion were applied, would qualify as neither positive nor normative, and opposing cases in which the statements would qualify as being both at the same time. Finally, I will devise an example in which the division is clear-cut but unintuitive.

The two-stage analysis of evaluations cannot be conclusive in each and every circumstance. A version of the Greenspan scenario brings this point home. If the contextual information is not rich enough, observers will be at a loss to decide what this manipulative central banker really meant in his press release (see (b) in Section II). Thus, readers who accept the groundwork may already be persuaded that the authoritative criterion cannot deliver an exhaustive division of economics. To reinforce the conclusion I will revisit Weber's analysis of the trade unionist, which is a locus classicus of the weak neutrality tradition. ${ }^{20}$

According to Weber, the social scientist aims at causally explaining the trade unionist's value commitments, and for this needs to rely on a coherent and reasonably complete view of what these commitments are. This crucial step, Weber adds, does not involve the social scientist in adopting, endorsing or approving of any of the trade unionist's values. Note first that if 'the trade unionist' referred to an historical individual the social scientist would not face the task that is being described. A biographer of, say, Clement Attlee is not required to turn the value judgments expressed by his character into a 
consistent whole. He may just tell the reader what he can reasonably conjecture, without trying to fill all gaps and apparent inconsistencies. However, 'trade unionist' here refers to an ideal-typical individual, which explains the stringent requirements that Weber mentions. It is part of the definition of an ideal-type that it is internally consistent and as complete as the theoretical investigation requires it to be. While emphasizing these two requirements correctly, Weber was wrong in not acknowledging that they created a severe tension with axiological neutrality. The following argument shows where Weber went astray.

Assume that a sequence of stage 2 decisions leads to the conclusion that a trade unionist make value judgments $\mathrm{V}_{1}, \ldots, \mathrm{V}_{n}$. Each of these judgments corresponds to a statement made by the representative individual, and a set of statements may or may not be logically consistent. If it is not, the question arises: which of the statements corresponding to $\mathrm{V}_{1}, \ldots, \mathrm{V}_{n}$ should be taken out in order to restore consistency? Supposing that consistency has been restored (or was there from the start), another question arises: how is the set to be expanded in order to provide a sufficiently complete picture? Weber assumes that logic is all that the social scientist needs in order to adjust the initial $\mathrm{V}_{1}, \ldots, \mathrm{V}_{n}$. But logic is insufficient: it just sets the constraints within which to pursue a rejection or acceptance policy. One wonders how social scientists would proceed if they did not retain the values they accept and eliminate the values they reject. It would be too bold to claim that this is the only basis for their choices. But it is surely one to be envisaged, and it fosters the suspicion that evaluations may permeate their ideal-typical reconstructions of value positions. The conclusion to draw is that this kind of work will often illustrate the indeterminacy between the positive and the normative. The argument is not meant to apply to ideal-types generally: it is a subspecies of them that I have been concerned with.

As far as economics goes, there is something to be said against the indeterminacy conclusion. Robbins (1932, p. 148) discusses the case of the consumer's preference for pork. Economists, he says, do not need to express the view that it is good or bad to consume pork in order to investigate the consumer's preference for this commodity. Granted that a preference involves an evaluation on the agent's part, this is a crude case of the ideal-types I have singled out, and it seems to raise very little problem indeed. The more general point about economics is that it introduces a good deal of its ideal-types by way of stipulation. There is the typical consumer, who likes or does not like pork; the typical von Neumann-Morgenstern agent, who is or is not risk averse; the typical optimizing agent of dynamic macroeconomics, who is or is not myopic; and so on. The stipulative definition secures consistency, and does not aim at completeness, because it serves only to highlight a particular logical or causal linkage.

I grant the exception constituted by this wide class of economic ideal-types, and concentrate instead on the, I think equally wide, class of those that approximate the trade unionist model. They are numerous in economic history and development economics. ${ }^{21}$ Strikingly, they occur in theoretical economics too, because, for argumentative purposes, economists need to construe idealtypes of their opponents' value positions. For instance, although few of today's readers are aware of this historical connection, Arrow's work in 1951 largely 
revolves around a refutation of Bergson's welfare economics; he restates his opponent's views by adding features so as to make up a complete evaluative system that falls prey to the impossibility theorem. Despite the non-Weberian twist of emphasizing the inconsistency of the resulting system, this is an idealtypical reconstruction all right, and it illustrates how the social scientist's own value commitments mingle with those attributed to the adversary. Thus, Arrow makes 'independence of irrelevant alternatives' part of Bergson's system, although nothing in the welfare economist's work supports this inclusion. ${ }^{22}$ There is only one explanation for this move. At the time, Arrow believed independence to be normatively compelling, so that Bergson would have to accept it willy-nilly.

My next objection is that the authoritative criterion is not exclusive. I base it on the way in which thick evaluative predicates function semantically (see Section IV). To illustrate, consider the following sentence from a hypothetical development economist:

If people are sufficiently well fed, and have access to basic education and health care, they do not live in a state of poverty.

The poverty predicate has an evaluative content, since the word means something undesirable. That it has a descriptive content seems equally clear: like the economist here, most of us believe that the concept of a 'poverty line' makes good sense, even if we disagree on where to place it. Thus, poverty is thick, and this entails that the elementary sub-statement expressed by 'they do not live in a state of poverty' is both logically evaluative and factual. On the assumption that the economist is sincerely asserting the whole statement, the two-stage analysis concludes that he makes both a judgment of value and a judgment of fact. Because these judgments accompany the same sub-statement, the authoritative criterion must classify it as being both normative and positive. Compare this conclusion with the earlier one reached in the trade unionist example; the criterion is not indeterminate anymore, but overdetermined.

There are manoeuvres to circumvent the objection, and as far as I can see they amount to interpreting the thick predicate-word 'poverty' as if it were ambiguous between the descriptive and the evaluative. By resolving the supposed ambiguity in the former way, one would conclude that the development economist is making only a judgment of fact. However, it is thickness, not ambiguity, that is at issue here. A thick predicate has its two sides simultaneously, not alternatively like an ambiguous predicate. This is not an incidental property, because the predicate would have no factual meaning if it lacked its evaluative meaning. To confirm that poverty fits this analysis, consider the following hypothetical retort to the development economist:

People who are sufficiently well fed, and have access to basic education and health care, do live in a state of poverty if they cannot satisfy more than these basic needs.

The two parties entertain opposite factual views about poverty. The reason for their disagreement is that they differ in evaluating the condition of enjoying barely the basic necessities of life. For the development economist this social condition cannot be factually the same as poverty because it is relatively 
desirable; the respondent reaches the opposite conclusion because he believes the condition to be definitely undesirable. The two parties will not settle their debate unless they discuss their conflicting evaluations as such. This illustrates the sense in which evaluations can be said to be semantically prior to the factual meanings. ${ }^{23}$

Finally, the authoritative criterion sometimes involves a counterintuitive division between the positive and the normative. Take an economist who investigates a value judgment made by some agent, and happens not only to endorse it, but also to make it clear that he does so. The criterion wants us to conclude that a normative statement was made, but this can be a completely unnatural conclusion, as the following concocted example suggests.

The Muslim part of the population thinks that it is despicable to eat pork, which affects the pork consumption in East London.

After writing this sentence, the economist adds: 'I myself disapprove of eating pork.' The first sentence on its own would straightforwardly belong to positive economics according to the two-stage analysis and the criterion applied in succession. However, the second sentence brings further information. The substatement expressed by 'It is despicable to eat pork' is logically evaluative and - it seems plausible to infer - sincerely asserted by the economist. Thus, the two-stage procedure leads to the conclusion that he has made a value judgment; and, applying the authoritative criterion, one would add that the statement expressed by the first sentence is normative after all.

This sounds like an odd result. Suppose that the economist wrote the second sentence as an incidental warning - say because, being a Muslim himself, he was worried that his involvement might lead him to misinterpret the facts. The change of status incurred by the statement would be the more troubling, since an exacting standard for positive economics motivated the troublesome addition! Note that I do not question the point that the economist made a value judgment. I argue that this is not by itself a reason for locating his work on the normative side of the division.

The East London example brings out the issue of the social scientist's diverse modes of endorsement. If the agent says 'I think $\mathrm{X}$ is good', the economist can approve of this either by expressing the same first-order evaluation - ' $I$ too think that $X$ is good'-or by making second-order evaluations such as 'It is good to think that $\mathrm{X}$ is good' or 'It is good for A to think that $\mathrm{X}$ is good'. The various modes are clearly distinct semantically, and one may submit that they do not carry the same consequences for the positive-normative distinction. Provided that the contextual information is rich enough, first-order endorsements will not be too much of a problem for the distinction. It is often possible to separate incidental value judgments, as in the East London example, from significant ones, as would be the case if the same economist had stated in detail why he thinks that eating pork is despicable. Second-order endorsements normally call for an explication, so one would not expect them to be incidental. When made in the absolute way ('It is good to...') they suggest that a value judgment is made, and this in turn signals a shift to the normative. When made in the relative way ('It is good for A to...'), only contextual information helps decide whether a value judgment is really made. I do not pursue the fine details here, meaning just to open up a 
scarcely noticed topic. With their loose concept of approbation, Weberians and Robbinsians have blurred semantic distinctions that prima facie matter to the positive-normative divide of economics.

\section{ENDS AND MEANS}

Both the strong and weak neutrality theses are often defended by invoking a time-honoured claim about instrumental reasoning. Scientists, it is often said, take as given the ends of those whom they advise, and explore the means only to achieve these ends. Because this requires no more than citing the relevant laws of nature, scientists manage to keep moral concerns entirely aside. Positivist and related writers, like Poincaré (1913) in a famous paper, make this claim for the applied natural sciences. Weber twisted it twice by adapting it to the problem of the theoretical social science, and in doing this made it part of his plea for value neutrality. This transformed the claim into another one: social scientists can and should take as given the ends of those agents whose actions they investigate. Starting from the given ends, social scientists explore the means to achieve them, and in their inquiry employ or uncover only laws of human action. One of Weber's supporting examples was the law of diminishing marginal utility; he argued that neoclassical theorists stated it without making any value judgment on the economic man's ends.

Logically, Weber's instrumental neutrality claim stands or falls by itself, irrespective of what is decided vis-à-vis his already examined distinction between making a value judgment and taking it as an object of study. The standard discussion of neutrality usually misses this point. The Weberians conflated the various components of their case in a way that made it difficult to analyse; at first sight it was a package, a matter of taking it or leaving it. This encouraged the perverse habit - among followers and opponents alike - of using 'ends' and 'values' more or less interchangeably. ${ }^{24}$

The instrumental neutrality claim is roughly plausible for such fields as military history, prehistory or archaeology, which do employ instrumental reasoning to explore human action and its products. But my subject is economics, and I will argue that the claim is unlikely to carry much weight there, because the end-means distinction is not really part of the economist's theoretical apparatus. The economist's tools for investigating purposeful action consist of preference and related notions, like utility. To be precise, there are two economic dichotomies: one opposing the preference relation to the objects it compares, and the other opposing the preference map to the feasibility constraints. Neither dichotomy matches the distinction between ends and means. There is a translation rule to go from the instrumental language to the preference language, but it does not work the other way round, as I will now explain.

Suppose that $\mathrm{E}$ and $\mathrm{E}^{\prime}$ are an agent's ends, while $\mathrm{M}$ and $\mathrm{M}^{\prime}$ are the means available to this agent. Instrumental reasoning leads to conclusions such as the following: $\mathrm{E}$ can be reached by means of either $\mathrm{M}$ or $\mathbf{M}^{\prime}$, but it is more appropriate to employ $\mathrm{M} ; \mathrm{E}^{\prime}$ can be reached again by means of either $\mathbf{M}$ or $\mathbf{M}^{\prime}$, but it is more appropriate to employ $\mathbf{M}^{\prime}$. To reproduce these conclusions, one introduces a preference map in which $(\mathrm{E}, \mathrm{M})$ is above $\left(\mathrm{E}, \mathrm{M}^{\prime}\right)$ and $\left(\mathrm{E}^{\prime}, \mathrm{M}^{\prime}\right)$ above $\left(\mathrm{E}^{\prime}, \mathrm{M}\right)$, assuming that each pair is feasible. More generally, every statement made using the instrumental language can be re-expressed in the 
other language. The procedure consists, first, in lumping together descriptions of the ends and means into states of affairs, and second in devising a feasible set of, as well as a preference relation on, these notional states. The converse translation is not always possible. The preference language makes it possible to compare $(\mathrm{E}, \mathrm{M})$ with $\left(\mathrm{E}^{\prime}, \mathrm{M}^{\prime}\right)$, i.e. to decide whether it is preferable to reach some end with some expense of means or to reach another end with another expense of means. By contrast, instrumental reasoning fixes the end and draws conclusions relative only to that end. It is unable to extend comparisons to several ends at a time.

By saying that the modern preference language is more expressive than the older instrumental language, I do not exactly make a novel point. However, those who make it often do not state it at the proper level of abstraction. For instance, Harsanyi (1976) mentions the availability of continuous trade-offs as a reason why the modern apparatus supersedes the old. This is irrelevant, because even irregular preferences have a greater expressive power than instrumental categories. However formulated, the point has apparently escaped the neutrality theorists' notice. Robbins imported the Weberian recommendation, 'Take ends as given', as if it applied to his field as well as to archaeology, and many economists have since followed him unthinkingly. Even such a basic example as the law of diminishing marginal utility cannot be discussed in the ends-means language. None the less, neoclassical economists have felt relief at the Weberian argument about ends and means.

The occasional cases in the field where ends (or objectives) are mentioned as such do not give much support to an instrumental neutrality claim. The monetarists who proposed the $k \%$ rule as an objective to be achieved by the central banks also discussed some fallible techniques to approximate it - e.g. to announce the rule publicly; not to pursue an interest rate objective at the same time; to compensate for the effect of currency fluctuations. Hence the $k \%$ rule provides an example of instrumental reasoning in economics which is both clear-cut and nontrivial. Does it support the claim that economists reason only from 'ends taken as given'? No. Inquiries on how to achieve it were just a small part of the monetarists' work. The latter were mostly concerned with defending the rule itself. Friedman's (1968) basic argument was that changes in the money stock had an effect on the real economy only in the short run: increasing or even accelerating inflation would be the only remaining long-run effect. This argument involved weighing long-run against short-run consequences-damages brought about by inflation against benefits ripped from temporary surges in employment. It was an evaluative argument throughout. It raised substantial complaints, but nobody objected to it on the formal ground that economics did not have to pass judgment on policy objectives. This was an important macroeconomic controversy, and one may be pleased in retrospect that it was not blocked by pedantry about end-neutrality. ${ }^{25}$

\section{CONCLUSIONS}

Section VII completes the argument of Section VI against the weak neutrality thesis and, by the same token, for the weak non-neutrality thesis. Since these two sections emphasized the positive-normative distinction, it may be useful to recast the salient points in the language of judgment. 
Remember that the two moderate theses conflict about the containment claim, and the latter says that (i) economics needs relatively few value judgments; (ii) the value judgments it needs are easy to identify; and (iii) these judgments can be separated not just logically, but practically, from the judgments of fact also made. I have argued to the contrary that economists make, and are justified in making, a large number of value judgments; that some of these are easy to pinpoint, but others are not; and that judgments of fact and of value often turn out to be inseparable from each other.

This threefold denial of the containment claim was warranted by my examination of thick predicates and ideal-typical reconstructions of evaluative positions in Section VI. It is surprising that weak neutrality theorists have neglected thick predicates and their logic, focusing instead on the evaluative good and a few predicates of ethical origin such as just. The early meta-ethical literature showed a similar unbalance, but the field has moved on since. In this respect, as in others, what contemporary economists borrow from philosophy proves to be outdated. Concerning ideal-types of the kind I have singled out, weak neutrality theorists have not paid sufficient attention to their pervasiveness, nor tried to analyse the peculiar mix of judgments that they tend to involve. Here, at least, they have the excuse of not having much philosophical work to call to the rescue; little has been written on ideal-types except along orthodox Weberian lines. The discussion of Section VII about 'ends as given' is mostly ad hominem as it stands. It should be continued by an argument against 'preferences as given', which consists in showing that social, and sometimes even individual, preferences are to be constructed by the economist, and his value judgments will naturally come into play at this juncture. I did not spell out the argument because it would parallel that developed for ideal-typical reconstructions of value positions. Weak neutrality theorists, such as Bergson, Samuelson and Arrow, all recognized that value judgments were needed to give the social welfare function a content, but only Arrow let the economist qua economist carry the task of filling out this content. Macroeconomists of all persuasions are unknowingly Arrovian. They have been active in the preference construction business, and it is fortunate that few of them have bothered about the neutrality principle they violate in doing so.

What remain common to the weak neutrality and non-neutrality theses are the following substantial claims. Positive economics includes (i) statements that are neither straightforwardly prescriptive nor logically evaluative; (ii) more controversial statements that do not count as prescriptive or logically evaluative because they are of the inverted-commas type; and (iii) statements that count as such, but for which there is no evidence that they are sincerely asserted by the economist. The traditional reason for isolating a core of positive economics is that one would like to compare it with the available accounts of scientific pursuits. For example, one might like to relate the law of demand to philosophical definitions of a law of nature, the testing of this law with that of the more established laws of physics, and so on. My conclusions preserve these applications, which the strong non-neutrality thesis would destroy. In a sense, the paper is a prerequisite to standard economic methodology, which takes the possibility of applying philosophy of science to the field as if it were obvious. 
Normative economics includes those statements that are prescriptive or logically evaluative, and are sincerely asserted by the economist. As in the description of positive economics, I am writing 'includes' instead of 'consists of', intending this as only a sufficient condition for an economic statement to be classified. What does not satisfy the offered conditions belongs to a buffer area between the positive and normative departments of economics. Section VI has exemplified where the division fails. Returning to the groundwork sections, I can extend the buffer area by including those logically evaluative statements that are clearly but insincerely asserted by the economist, and those equivocal statements that can be regarded as neutral only if one stretches the understanding of the inverted by commas use.

To keep the paper within limits, I omitted the topic of interpersonal comparisons of utility and preference, despite the historical fact that neutrality theorists have often described them as evaluative. This view is not as common now as it was in Robbins's time, and its flaws are perhaps sufficiently clear for the omission to be excused. ${ }^{26}$ It is more of a problem that I said nothing about causal attribution as a way of separating positive from normative reasoning, although both Weber and Keynes did envisage this demarcation criterion. Given the recent outburst of work on causality, their argument is not to be taken casually, so I have refrained from discussing it. I also left out the experimental study of the people's normative attitudes, an intriguing area in which the positive and the normative are intertwined. ${ }^{27}$ However, the major absentee is rationality, which simply cannot be handled in the length of a paper. One of the intuitions that turn the scale against neutrality is the pervasiveness of decision- and game-theoretic arguments in today's economics, an intellectual phenomenon that the older writers can be excused for not foreshadowing. Despite so many lacunae, I hope to leave the debate about value judgments and value neutrality in a better state than that in which I found it.

\section{ACKNOWLEDGMENTS}

This is a much revised version of a paper initially entitled 'Value Judgments and Value Neutrality in Economics. A Perspective from Today' (2001-18, Laboratoire d'économétrie, CNRS \& Ecole Polytechnique) and given at LSE, Université d'Aix-Marseille, Katholieke Universiteit Leuven, Université de Caen, and, as an invited lecture, at the ECAP (2002) and INEM (2004) conferences. My special thanks to D. Hausman, who provided extremely valuable comments at each successive stage; today's paper would be altogether different without his philosophical input. I am also grateful to A. Clark, J. Davis, S. Finlay, M. van Hees, B. Hill, I. Levi, B. Manin, R. Ogien, W. Rabinowicz, F. Schokkaert, M. Steuer, B. Walliser and A. Wolfelsperger, for their detailed comments, and to the editor of Economica for his guidance. I gratefully acknowledge support from the LSE and the Lachmann Foundation when I wrote the initial version.

\section{NOTES}

1. Von Mises and other Austrians also adapted the value language to economics, but they appear to have influenced mainstream economics mostly through Robbins's account.

2. Blaug (1998) quickly surveys these developments.

3. This argument is usually stated without details; see, e.g. Hylland (1986) and Fleurbaey (1995, chapter 1). 
4. Mongin $(1999,2000)$ investigates Arrow's work with a view to showing that he does not refrain from taking sides, contrary to the popular view of social choice theory as mostly formalistic.

5. Arrow's (1984a, b) papers on decision-making contains numerous hints in this direction.

6. Economic methodology has for the most part contented itself with re-describing available positions in their own terms, which leaves little hope of settling their disagreements; see e.g. the surveys by Hutchison (1964) and Machlup (1978).

7. Others would identify the judgment with the statement made, taking it to be closer to a logical entity than I do in the present account. As to the distinction between sentence, statement, and utterance or inscription, see e.g. Haack (1978).

8. It is not so clear whether the other meta-ethical positions were recognized by twentiethcentury economists. Some history of thought would be welcome here.

9. The meaning of this restriction is clarified below.

10. While analytical statements are automatically endowed with a truth value, non-analytical statements may or may not have one. Hence I remain consistent with my policy of separating the value neutrality from the truth value problem.

11. Consider the following sentence: 'In her speech Mrs Thatcher expressed her belief that active trade unions were bad for the economy.'

12. I use 'prescription' in the same encompassing sense as I do 'evaluation', i.e. to cover utterances or inscriptions, sentences and statements, as well as judgments. This paper makes no effort to distinguish obligations from prescriptions, despite the interesting dissimilarities that could be pointed out.

13. See also "Modern economic theory draws a sharp distinction between positive economics, which explains the working of the economic system, and welfare economics, which prescribes policy' (Scitovsky, 1941, p. 77).

14. In philosophers' jargon, an evaluative predicate supervenes on a list of descriptive predicates. Without using the word, Arrow aptly summarizes what it means (1951, in 1963, p. 112). Hurley (1989) was the first to discuss supervenience in relation to Arrow and economics at large.

15. See e.g. Sen (1982); Hausman and McPherson (1996); Mongin and d'Aspremont (1998); Hausman (2000).

16. This passage is discussed in Klappholz (1964) differently and, at a crucial stage, wrongly (when, in a typically Robbinsian way, he defends neutrality in terms of 'is' and 'ought').

17. Weber (1922) exposed the non sequitur in the first claim by means of the famous distinction between value judgment and value relation (Werturteil and Wertbeziehung), which has become bread and butter for later methodologists.

18. Little (1950, p. 69) stands apart. He is aware of the distinction but denies that it should be made: 'the value judgments which enter welfare economics are of an ethical kind'. His emotivist conception of evaluations may be responsible for this sweeping claim.

19. The argument was a LSE collective creation, involving Lipsey as well (see Lancaster, 1958, p. 464, n. 1, and Archibald, 1959, p. 322, n. 2). It originates in a hint from Little (1950, p. 38).

20. See, 'Der Sinn der Wertfreiheit' in Gesammelte Aufsätze zur Wissenschaftslehre (Weber, 1922, pp. 500-2). Elsewhere in the same paper, Weber explains what it means for the scientist neutrally to deal with a value judgment (e.g. p. 485). 'Die Objektivität sozialwissenschaftlicher und sozialpolitischer Erkenntnis' is briefer on the same topic but none the less important because it draws the connection, to be discussed below, with the topic of instrumental rationality.

21. Think e.g. of Rostow's (1965) construction of 'taking off' in his stage theory of economic growth or the recent work on 'globalization' in development economics.

22. Bergson (1954) rightly complained that he had been misrepresented; see the assessment in Mongin (2000).

23. Weber (1922, p. 516) implicitly discussed thickness when considering progress. He found it so heavily value-loaded that he recommended that social scientists give it up altogether. This would be a desperate move; it would destroy a good deal of interesting work carried out by historians.

24. E.g. 'Economics is neutral as between ends. Economics cannot pronounce on the validity of ultimate judgments of values' (Robbins, 1932; in 1935, p. 147). The conflation of 'ends' and 'values' is also common in welfare economics, as Sen (1970, p. 62) mentions in passing.

25. Friedman's (1953) soothing view of neutrality at the beginning of the notorious essay clashes with his general practice of making recommendations and arguing for them. More on this in Hirsch and de Marchi (1990).

26. For a good early discussion see Little (1950, ch. 5). Contemporary views are summarized in Elster and Roemer (1991).

27. Miller (1992) and Schokkaert (1999) survey this quickly growing area. 


\section{REFERENCES}

Archibald, G. C. (1959). Welfare economics, ethics, and essentialism. Economica, NS 26, 316-27. Arrow, K. J. (1951). Social Choice and Individual Values. New Haven, Conn.: Yale University Press; 2nd edn 1963.

- (1984a). Collected Papers, Vol. 1: Social Choice and Justice. Oxford: Blackwell.

(1984b). Collected Papers, Vol. 3: Individual Choice under Uncertainty. Oxford: Blackwell.

BERGSON (BURK), A. (1938). A reformulation of certain aspects of welfare economics. Quarterly Journal of Economics, 52, 310-35.

(1954). On the concept of social welfare. Quarterly Journal of Economics, 68, 233-52.

Blaug, M. (1998). The positive-normative distinction. In J. Davis, W. Hands and U. Mäki (eds.), Handbook of Economic Methodology. Cheltenham: Elgar, pp. 370-4.

Elster, J. and Roemer, J. E. (eds.) (1991). Interpersonal Comparisons of Well-Being. Cambridge: Cambridge University Press.

Fleurbaey, M. (1996). Théories économiques de la justice. Paris: Economica.

Friedman, M. (1953). The Methodology of Positive Economics. Chicago: Chicago University Press. (1968). The role of monetary policy. American Economic Review, 58, 1-17.

GEACH, P. T. (1956). Good and evil. Analysis, 17, 33-42.

GraAfF, J. DE V. (1957). Theoretical Welfare Economics. Cambridge: Cambridge University Press.

HaACK, S. (1978). Philosophy of Logics. Cambridge: Cambridge University Press.

HARE, R. M. (1952). The Language of Morals. Oxford: Clarendon Press. - (1957). Geach: good and evil. Analysis, 18, 103-12.

Harsanyi, J. C. (1976). Essays on Ethics, Social Behavior, and Scientific Explanation. Dordrecht: Reidel.

Hausman, D. M. (2000). Revealed preference, belief, and game theory. Economics and Philosophy, 16, 99-115.

- and McPherson, M. S. (1996). Economic Analysis and Moral Philosophy. Cambridge: Cambridge University Press.

Hirsch, A. and DE MARCHI, N. (1990). Milton Friedman: Economics in Theory and in Practice. Ann Arbor, Mich.: University of Michigan Press.

Hume, D. (1739). A Treatise on Human Nature. ed. L. A. Selby-Bridge, Oxford: Clarendon Press, 1960.

Hurley, S. (1989). Natural Reasons. Oxford: Oxford University Press.

Hutchison, T. W. (1964). 'Positive' Economics and Policy Objectives. London: Allen \& Unwin.

Hylland, A. (1986). The purpose and significance of social choice theory: some general remarks and an application to the 'Lady Chatterley Problem'. In J. Elster and A. Hylland (eds.), Foundations of Social Choice Theory. Cambridge: Cambridge University Press.

Kalinowski, G. (1972). La logique des norme. Paris: Presses Universitaires de France.

KeYneS, J. N. (1890). The Scope and Method of Political Economy, 4th edn 1917. New York: Kelley Reprints, 1963.

KLAppholz, K. (1964). Value judgments and economics. British Journal for the Philosophy of Science, 15, 97-114.

LANCASTER, K. (1958). Welfare propositions in terms of consistency and expanded choice. Economic Journal, 68, 464-70.

LIPSEY, R. (1963). Introduction to Positive Economics. London: Weidenfeld \& Nicolson; 2nd edn 1966.

LitTle, I. (1950). A Critique of Welfare Economics. Oxford: Oxford University Press; 2nd edn 1957.

Machlup, F. (1978). Methodology of Economics and Other Social Sciences. New York: Academic Press.

MANNHEIM, K. (1936). Ideology and Utopia. London: Routledge.

Miller, D. (1992). Distributive justice: what the people think. Ethics, 102, 555-93.

Mongin, P. (1999). Normes et jugements de valeur en économie normative. Information sur les sciences sociales/Social Science Information, 38, 521-53.

(2000). Is there progress in normative economics? Lecture given at the ESHET 2000 Conference, Universität Graz.

- and D'Aspremont, C. (1998). Utility theory and ethics. In S. Barberà, P. Hammond and C. Seidl, Handbook of Utility Theory, Vol. 1. Dordrecht: Kluwer, pp. 371-481. 
Myrdal, G. (1958). Value in Social Theory, ed. and introd. P. Streeten. London: Routledge.

PHILliPS, A. W. (1958). The relation between unemployment and the rate of change of money wage rates in the United Kingdom, 1861-1957. Economica, NS 25, 283-99.

Pigou, A. (1920). The Economics of Welfare. London: Macmillan.

Poincaré, H. (1913). La morale et la science. In Dernières pensées. Paris: Flammarion.

RobBins, L. (1932). An Essay on the Nature and Significance of Economic Science. London: Macmillan; 2nd edn 1935.

Rostow, W. (1965). The Stages of Economic Growth. Cambridge: Cambridge University Press.

Samuelson, P. A. (1947). The Foundations of Economic Analysis. Cambridge, Mass.: Harvard University Press.

SCHOKKAERT, E. (1999). M. Tout-le-monde est postwelfariste: opinions sur la justice distributive. Revue économique, 50, 811-31.

Scitovsky, T. (1941). A note on welfare propositions in economics. Review of Economic Studies, $\mathbf{9}$, $77-88$.

SEN, A. (1970). Collective Choice and Social Welfare. San Francisco: Holden Day.

(1979). Utilitarianism and welfarism. Journal of Philosophy, 76, 463-89.

(1982). Choice, Welfare and Measurement. Oxford: Blackwell.

(1991). Welfare, preference and freedom. Journal of Econometrics, 50, 15-29.

von Wright, G. H. (1983). Philosophical Papers, Vol. 1: Practical Reason. Oxford: Blackwell.

Weber, M. (1922). Gesammelte Aufsätze zur Wissenschaftslehre. Tübingen: Mohr \& Siebeck; partial translation as The Methodology of the Social Sciences. New York: Macmillan.

Williams, B. (1985). Ethics and the Limits of Philosophy. London: Fontana Press. 